\title{
Prospective Study to Evaluate Effect of Autologus Plasma Injection in the Wound Site immediately after Primary Wound Closure
}

\author{
Fawzy Ahmed Hamza, Ahmed Taha Sayed, \\ Mohamed Mustafa Mohamed Mohamed Saeed* \\ Plastic surgery Department, Al-Azhar University \\ * Corresponding author: Mohamed Mustafa Mohamed Mohamed Saeed, E-mail: mhmd.saeed1988@gmail.com
}

\begin{abstract}
Background: Healing of wounds is considered as a complex and dynamic process, Platelets play an important role in the process of wound healing because it releases many growth factors that may be valuable in improving the results of the healing process.

Aim of the Work: The purpose of this study was to evaluate the effect of autologus plasma injection in the wound site immediately after wound closure on the process of wound healing.

Patients and Methods: The study was conducted on 60 patients having wounds at different sites of the body either post-traumatic or post-operative. They were grouped into two groups: Group A received autologus plasma injection in the wound site immediately after primary wound closure together with the usual wound care while the other group B received only the usual wound care without plasma injection. We have evaluated the wound healing process parameters as vascularity, pigmentation, pliability, pain, stiffness, the cosmetic results and development of complications using the Patient And Observer Scar Assessment Scale (POSAS) Score.

Results: We have found that the results of the wound healing process have improved much in group A which received autologus plasma injection than that was found in group B that didn't receive plasma injection regarding vascularity, pigmentation, pliability, pain, wound healing complications, cosmetic results and patients' satisfaction.

Conclusion: Autologus plasma injection in the wound site immediately after wound closure has enhanced the wound healing process, gave better cosmetic results and led to more patients' satisfacion because it contains abundant growth factors, cytokines and biologically active substances.

Keywords: Wound healing, Autologus Plasma, Platelet-rich Plasma, Platelet-Poor Plasma, Cosmetic, Growth factors, growth mediators.
\end{abstract}

\section{INTRODUCTION}

Healing of wounds is considered as a complex process because as when a wound starts healing, the process resolves with complete wound cessation. Healing of acute and chronic wounds can be affected by patient factors and/or wound factors. Restarting a wound with impaired healing is difficult because good standard wound care does not always provide an improved healing results ${ }^{(1)}$.

Platelets play important roles in wound healing because of their hemostatic function and concentrated levels of biologically active substances as cytokines and growth factors ${ }^{(2)}$.

Platelet rich plasma (PRP) is considered to be advanced wound therapy for wounds. PRP is a highly concentrated autologous solution of plasma obtained from a patient's own blood. PRP contains platelets that release many growth factors that may be valuable in numerous dermatological applications. Autologous PRP contains cytokines, growth factors, chemokines and fibrin derived from the patient's blood. The mechanism of action of platelet rich plasma is thought to be the molecular and cellular induction of normal wound healing responses (3).

The wide popularity of PRP came from its promise as a safe and natural alternative to surgery. Using PRP has promoted the wound healing process being an organically based therapy derived from patient's own blood. PRP has been shown to be effective in tissue healing because PRP is known to be effective in many aspects of tissue regeneration ${ }^{(4)}$.

Many studies proposed that platelets contain an abundance of growth factors and cytokines that can affect inflammation, postoperative blood loss, infection, osteogenesis, wound, muscle tear, and soft tissue healing. Research nowadays shows that platelets also release many bioactive proteins that attract macrophages, mesenchymal stem cells, and osteoblasts that not only promote removal of degenerated and necrotic tissue but also enhance tissue regeneration and healing ${ }^{(5)}$. 


\section{AIM OF THE WORK}

The purpose of this study was to evaluate the effect of autologus plasma injection in the wound site immediately after primary wound closrue on the process of wound healing.

\section{PATIENTS AND METHODS \\ Study Design:}

This is a prospective randomized controlled study which was conducted on 60 patients which was grouped into two groups: Group A (Plasma-injected) received plasma injection and Group B (Control group) not injected with plasma.

The study was approved by the Ethics Board of Al-Azhar University.

\section{Inclusion criteria:}

- All males and females patients.

- Age from 5 to 60 years.

- Wounds at any part of the body either posttraumatic or post-operative.

\section{Exclusion criteria:}

- Psychologically unstable Patients.

- Patients refusing injection.

Methods:

This study was conducted on patients attending to Al-Azhar University Hospitals and Om El-Masryeen General Hospital in the period between January 2018 to October 2018.

After proper history taking, local wound examination followed by signing an informed consent with agreement for injection of plasma in the wounds, blood volume was withdrawn approximately $5-40 \mathrm{ml}$ depending on the wound length from the uninvolved upper limb of each patient in the intervention group (group A) using sterile syringes then putting them into tubes containing Sodium Citrate for anticoagulation.

The blood was immediately centrifuged using an electronic centrifuge at 3500 RPM for 10 minutes. Then, the whole plasma fraction was obtained and activated by using calcium gluconate solution $10 \%$ as $1 \mathrm{ml}$ for every $10 \mathrm{ml}$ of Plasma.

The procedure was done under anethesia either local anethesia by Xylocaine $2 \%$ sloution in the most of the post-traumatic cases or general and spinal anethesia in the post-operative cases.

Most of the wounds of both groups were sutured into 2 layers: subcutaneous layer by using abosrbable, synthetic, braided suture material (polyglactin) Vicryl ${ }^{\circledR} 2 / 0,3 / 0$ and 4/0 while the cutaneous layer was sutures by synthetic, non-absorbable, monofilamentous suture material (polypropylene) Prolene ${ }^{\circledR} 3 / 0$, $4 / 0,5 / 0$ and $6 / 0$, subcuticular or simple interrupted.

Immediately after cleansing and wound closure, the plasma was injected into the subcutaneous plane at either sides of the wound using sterile syringes, each centimeter of wound length received one milliliter of plasma, $0.5 \mathrm{ml}$ on each side, then wound dressing was done.

Routine dressings were doen by using sterile gauze together with antibiotic cream and all cases of both groups have received oral antibiotics after the procedure to guard against infection.

All patients of both groups were followed up after 1 week, 1 month, 2 and 3 months post injection. Also self-care of wounds by dressings. Medical Photography for each follow-up visit. The wound healing process was assessed regarding clinical assessment, timing of wound healing, vascularity, pigmentation, pliability, thickness and development of complications.

In this study we have used The POSAS Score for assessment of the wound healing process as its more comprehensive, easy to use, provides both the observers' and the patient's insights, had a higher correlation with patient's opinion and proved to be more advantageous than other tools ${ }^{\left({ }^{6}\right)}$.

\section{Statistical Analysis}

Data were collected, revised, coded and entered to the Statistical Package for Social Science (IBM SPSS) version 23. The quantitative data were presented as mean, standard deviations and ranges when their distribution found parametric. Also qualitative variables were presented as number and percentages. The comparison between groups regarding qualitative data was done by using Chi-square test. The comparison between two independent groups with quantitative data and parametric distribution were done by using Independent t-test. The confidence interval was set to $95 \%$ and the margin of error accepted was set to $5 \%$. So, the p-value was considered significant at the level of $<0.05$.

\section{RESULTS}

Table (1) Demographic data and risk factors among study groups 
Prospective Study to Evaluate Effect of Autologus Plasma Injection in the Wound Site...

\begin{tabular}{|c|c|c|c|c|c|c|}
\hline & Group A & Group B & \multirow{2}{*}{ Test value } & \multirow{2}{*}{ P-value } & \multirow{2}{*}{ Sig. } \\
\hline & & \begin{tabular}{|l|} 
No. $=30$ \\
\end{tabular} & \begin{tabular}{|l|} 
No. $=30$ \\
\end{tabular} & & & \\
\hline \multirow{2}{*}{ Age } & \begin{tabular}{|l|} 
Mean \pm SD \\
Range \\
\end{tabular} & \begin{tabular}{|l|}
$33.33 \pm 6.79$ \\
$15-48$ \\
\end{tabular} & \begin{tabular}{|l|}
$31.37 \pm 10.34$ \\
$7-46$ \\
\end{tabular} & $0.871 \bullet$ & 0.387 & NS \\
\hline & $\begin{array}{l}\leq 30 \\
>30 \\
\end{array}$ & \begin{tabular}{|l|}
$9(30.0 \%)$ \\
$21(70.0 \%)$ \\
\end{tabular} & \begin{tabular}{|l|}
$11(36.7 \%)$ \\
$19(63.3 \%)$ \\
\end{tabular} & $0.300^{*}$ & 0.584 & NS \\
\hline Sex & \begin{tabular}{|l|}
$\begin{array}{l}\text { Female } \\
\text { Male }\end{array}$ \\
\end{tabular} & \begin{tabular}{|l|}
$21(70.0 \%)$ \\
$9(30.0 \%)$ \\
\end{tabular} & \begin{tabular}{|l|}
$22(73.3 \%)$ \\
$8(26.7 \%)$ \\
\end{tabular} & $0.082^{*}$ & 0.774 & NS \\
\hline Smoking & \begin{tabular}{|l|} 
No \\
Yes \\
\end{tabular} & \begin{tabular}{|l|}
$25(83.3 \%)$ \\
$5(16.7 \%)$ \\
\end{tabular} & \begin{tabular}{|l|}
$25(83.3 \%)$ \\
$5(16.7 \%)$ \\
\end{tabular} & $0.000^{*}$ & 1.000 & NS \\
\hline Underling Diseases & $\begin{array}{l}\text { Negative } \\
\text { Diabetic } \\
\text { Hypertensive }\end{array}$ & \begin{tabular}{|l|}
$28(93.3 \%)$ \\
$1(3.3 \%)$ \\
$1(3.3 \%)$ \\
\end{tabular} & \begin{tabular}{|l}
$26(86.7 \%)$ \\
$2(6.7 \%)$ \\
$2(6.7 \%)$
\end{tabular} & $0.741^{*}$ & 0.690 & NS \\
\hline Chronic medications & $\begin{array}{l}\text { No } \\
\text { Hypoglycemic } \\
\text { Insulin } \\
\text { ACE inhibitor } \\
\text { Corticosteroids }\end{array}$ & \begin{tabular}{|l|}
$28(93.3 \%)$ \\
$0(0.0 \%)$ \\
$1(3.3 \%)$ \\
$1 \quad(3.3 \%)$ \\
$0(0.0 \%)$ \\
\end{tabular} & \begin{tabular}{|l|}
$26(86.7 \%)$ \\
$2(6.7 \%)$ \\
$0(0.0 \%)$ \\
$2 \quad$ \\
$0(0.0 \%)$
\end{tabular} & $3.407^{*}$ & 0.333 & NS \\
\hline
\end{tabular}

$\bullet:$ Independent t-test; *: Chi-square test

Table (1) illustrates that the mean age in group A was 33.33 years while the mean age in group B was 31.37 and there were 21 female and 9 male in group A in relation to 22 female and 8 male in group B. The differences in the demographic data gave non significant results with p-value $<0.05$.

Table (2) Wound sites in the body among study groups

\begin{tabular}{|l|l|l|l|l|l|}
\hline Wound Site & Group A $($ No. $=30)$ & Group B $($ No. $=\mathbf{3 0})$ & Test value* & P-value & Sig. \\
\hline Face & $7(23.3 \%)$ & $6(20.0 \%)$ & 0.351 & 0.554 & NS \\
\hline Breasts & $5(16.7 \%)$ & $5(16.7 \%)$ & 0.000 & 1.000 & NS \\
\hline Neck & $1(3.3 \%)$ & $0(0.0 \%)$ & 2.069 & 0.150 & NS \\
\hline Lower limbs & $0(0.0 \%)$ & $3(1.0 \%)$ & 1.017 & 0.313 & NS \\
\hline Arms & $4(13.3 \%)$ & $6(20.0 \%)$ & 3.268 & 0.071 & NS \\
\hline Abdomen & $11(36.7 \%)$ & $9(30.0 \%)$ & 0.071 & 0.790 & NS \\
\hline Back & $1(3.3 \%)$ & $0(0.0 \%)$ & 2.069 & 0.150 & NS \\
\hline Forearm & $1(3.3 \%)$ & $1(3.3 \%)$ & 0.000 & 1.000 & NS \\
\hline
\end{tabular}

*: Chi-square test

Table (2) illustrates the different sites of the wounds in the body among the study groups which was variable however gave non significant values with $\mathrm{p}$-value $<0.05$.

Table (3) The Mean POSAS Score through all follow up visits among study groups

\begin{tabular}{|c|c|c|c|c|c|c|}
\hline & & $\begin{array}{l}\text { Group } \\
(\text { No. }=30)\end{array}$ & $\left|\begin{array}{l}\text { Group } \\
(\text { No. }=30)\end{array}\right|$ B & Test value & P-value & Sig. \\
\hline Mean POSAS & \begin{tabular}{|l|} 
Mean \pm SD \\
Range \\
\end{tabular} & \begin{tabular}{|l|}
$39.35 \pm 9.87$ \\
$29.5-48.75$ \\
\end{tabular} & $\begin{array}{l}45.67 \pm 8.71 \\
29.25-60.75 \\
\end{array}$ & $2.630 \bullet$ & 0.011 & $\mathrm{~S}$ \\
\hline Complications & $\begin{array}{l}\text { No } \\
\text { Yes }\end{array}$ & \begin{tabular}{|l|}
$28(93.3 \%)$ \\
$2(6.7 \%)$ \\
\end{tabular} & $\begin{array}{l}25(83.3 \%) \\
5(16.7 \%) \\
\end{array}$ & $1.456^{*}$ & 0.228 & NS \\
\hline
\end{tabular}

$\because$ Independent t-test; *: Chi-square test

Table (3) Table illustrates that the Mean POSAS Score has improved significantly with $\mathrm{p}$ value $<0.05$ in group A (Plasma-injected) which received plasma injection than in group B (Control group) which received only the usual wound care without plasma injection.

Figure (1) Mean POSAS Score of the study groups during the follow up visits showing that group A had a lower, hence better score during all follow up visits than in group B indicating the enhanced results of the wound healing process of group A. 


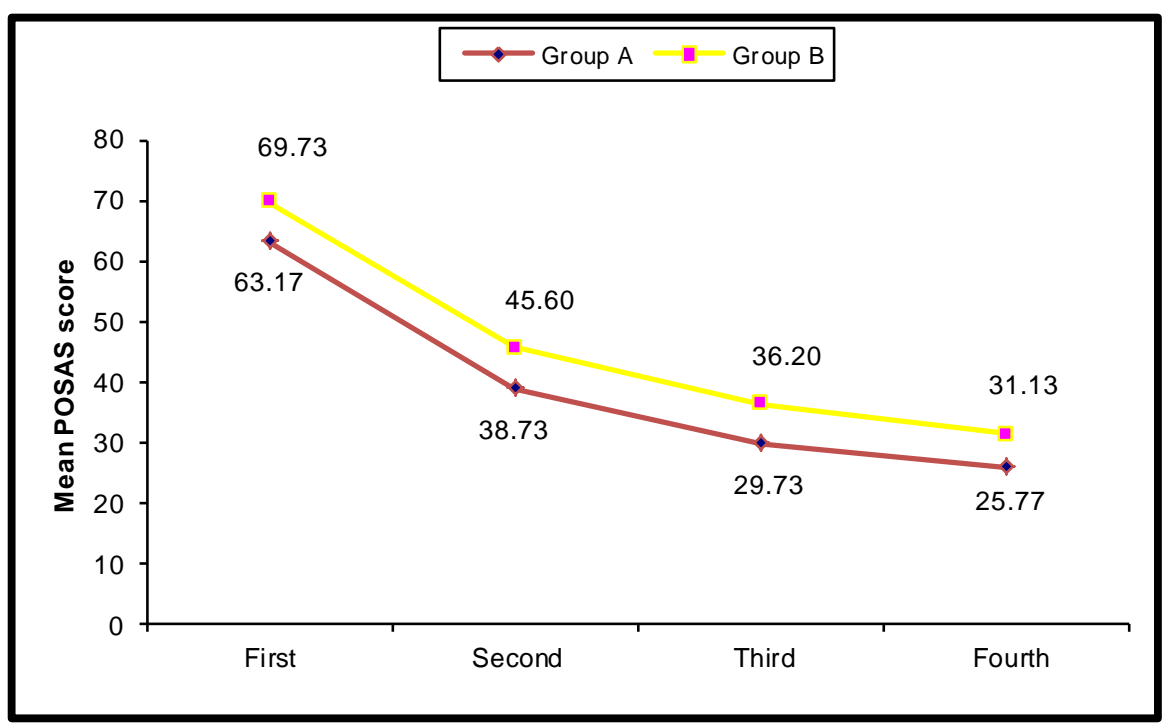

\section{DISCUSSION}

Wound healing process is greatly affected by many factors either general as age, nutritional status, debilitating diseases and chronic steroid use and chemotherapy or local wound factors as vascularity, infection, venous drainage, tension, irradiation and mobilization. Following injury, the end result of the process of wound healing is the sum of many various factors: Coagulation, inflammation, matrix synthesis, angiogenesis, fibroplasia, epithelialization, contraction, remodeling and scar maturation ${ }^{(7)}$.

This study included 60 patients having wounds at different parts of the body. The patients were grouped into two groups: group A (Plasma- injected group) ( $\mathrm{n}=30)$ which received plasma injection immediately after wound closure together with the routine dressings and group B (Non-injected group) $(n=30)$ that received only the routine dressings without plasma injection

We have used the whole plasma fraction in partial agreement with Almdahl $\boldsymbol{e t}$ al. ${ }^{(8)}$ and Lawlor et al. ${ }^{(9)}$ who used plateletrich plasma and different from Driver et al. ${ }^{(10)}$, Frykberg et al. ${ }^{(11)}$ and Saad et al. ${ }^{(12)}$ who used platelet-rich plasma gel.

Driver et al. ${ }^{(10)}$ and Saad et al. ${ }^{(12)}$ dealt with diabetic foot ulcers while Kazakos et al. (12) studied acute limb soft tissue wounds and Frykberg et al. ${ }^{(11)}$ tried plasma with chronic non-healing wounds. In this study we have used plasma in acute wounds either post-traumatic or post-operative.

We have injected the plasma into the wound edges in the subcutaneous plane, immediately after wound closure while Lawlor et al. ${ }^{(9)}$ sprayed the platelet poor plasma on the bed of the wound and injected the platelet rich plasma into the wound edges in the subcutaneous plane prior to closure. Almdahl et al. ${ }^{(8)}$ sprayed the wounds after operation with platelet-rich plasma. Driver et al. (10), Frykberg et al. ${ }^{(11)}$ and Saad et al. ${ }^{(12)}$ used the platelet rich plasma gel as a dressing for the wound

The mean age was 33.3 with S.D. \pm 6.79 in group A as the oldest was 48 years old and the youngest was 15 years old while in group B the mean age was 31.37 with S.D. \pm 10.34 as the oldest was 46 years old and the youngest was 7 years old. Sex distribution among the patients varied as there were 21 females and 9 males in group A, while there were 22 females and 8 males in group B.

Regarding risk factors for wound healing, there were 5 smokers in group A and 5 smokers in group $\mathrm{B}$ and 1 diabetic patient in group $\mathrm{A}$ and 2 diabetic patients in group B.

Regarding the site of the wound there were seven facial wounds in group $\mathrm{A}$ and six facial wounds in group B, eleven abdominal wounds in group $A$ and nine abdominal wounds in group B, five breast wounds in group $\mathrm{A}$ and five breast wounds in group $\mathrm{B}$, four arm wounds in group $A$ and six arm wounds in group B.

All associated factors that might be advantageous in wound healing process as smoking, diabetes, steroid usage, wound site and length showed no significant differences between the two groups with p-value $>0.05$. 
We used The POSAS Score for assessment of the wound healing process as its more comprehensive, easy to use, provides both the observers' and the patient's insights, had a higher correlation with patient's satfisfaction.

Almdahl et al.$^{(8)}$ used ASEPSIS score in his study while Driver et al. $^{(\mathbf{1 0 )}}$ and Saad $\boldsymbol{e t}$ al. (12) measured the ulcer's dimensions in assessment of the wound healing process.

The Mean POSAS Score of all follow up visits in group A was (39.35) and in group B (45.67) giving lower score indicating better results in group A (Plasma- injected group) than group B (Non-injected group) which was statistically significant difference with p-value $<0.05$ in vascularity, pigmentation, pliability, stiffness and patient's satisfaction.

We found an improved pliability, better color difference and more patients' satisfaction in group A than in group B in the first follow up visit, while vascularity improved much starting from the second, third and fourth follow up visits at one month, 2 months and 3 months respectively. In agreement with Driver et al. ${ }^{(10)}$ and Saad et al. ${ }^{(12)}$ who found that PRP gel enhances healing of chronic diabetic foot ulcers. In contrast to Almdahl et al. ${ }^{(8)}$ who found that topical application of autologous platelet-rich plasma did not reduce the rate of surgical site infection, and in contrast to Lawlor et al. ${ }^{(9)}$ who concluded that plateletrich plasma did not decrease the incidence wound complications.

Only 2 cases in group A $(6.6 \%)$ were complicated by developing wound dehiscence and hypertrophic scar while there were 4 complicated cases in group B $(13.3 \%)$ that developed hypertrophic scar, wound dehiscence, hyperpigmentation. No statistically significant difference with $p$-value $>0.05$ in development of complications in both groups. The hypertrophic scarring that occurred in 2 cases one in each group was at the lateral side of the arm and shoulder which may be attributed to the tendency of the wound site toward hypertrophic scarring formation. Lawlor et al. ${ }^{(9)}$ reported wound complications in $9(23 \%)$ of 40 of PRP group and $9(22 \%)$ of 41 of non-PRP in his study while Almdahl $\boldsymbol{e t}$ al. ${ }^{(8)}$ told that 9 patients $(13 \%)$ in the treatment group and eight (11\%) in the control group experienced harvest site infection.

\section{CONCLUSION}

We conclude that autologus plasma injection in the wound site immediately after wound closure improved the wound healing process, gave better cosmetic results and led to a more patients' satisfacion because it contains abundant growth factors, cytokines and biologically active substances.

\section{REFERENCES}

1. Menke NB, Ward KR, Witten TM et al. (2007): Impaired wound healing. Clinics in dermatology, 25(1):19-25.

2. Garraud, Olivier, Gamal Badr et al. (2017): Wound healing: Time to look for Intelligent Natural Immunological approaches. BMC immunology, 18(1):23-24

3. Deng W, Boey J, Chen B et al. (2016): Platelet-rich plasma, Bilayered acellular matrix grafting and negative pressure wound therapy in diabetic foot infection. Journal of wound care, 25(7):393-397.

4. Janis JE, Kwon RK and Lalonde DH (2010): A practical guide to wound healing. Plastic and reconstructive surgery, 125(6):230e-244e.

5. Kothari K (2017): Role of platelet rich plasma The current trend and evidence. Indian Journal of Pain, 31(1):1-3.

6. Draaijers J, Van De Kar, Annekatrien L et al. (2005): Reliable and feasible evaluation of linear scars by the Patient and Observer Scar Assessment Scale. Plastic and reconstructive surgery, 116(2):514-522

7. Velnar T, Bailey $T$ and Smrkolj $V$ (2009): The wound healing process: an overview of the cellular and molecular mechanisms. Journal of International Medical Research, 37(5):1528-1542.

8. Almdahl SM, Veel T, Halvorsen P et al. (2011): Randomized prospective trial of saphenous vein harvest site infection after wound closure with and without topical application of autologous platelet-rich plasma. Eur J Cardiothorac Surg., 39(1):4448.

9. Lawlor DK, Derose G, Harris KA et al. (2011): The role of platelet-rich plasma in inguinal wound healing in vascular surgery patients. Vasc. Endovascular Surg., 45(3):241-245.

10. Driver VR, Hanft J, Fylling CP et al. (2006): Autologel Diabetic Foot Ulcer Study Group. A prospective, randomized, controlled trial of autologous platelet rich plasma gel for 
the treatment of diabetic foot ulcers. Ostomy Wound Management, 52(6):68-74.

11. Frykberg RG, Carman D et al.(2010): Chronic wounds treated with a physiologically relevant concentration of platelet rich plasma gel a prospective case series. Ostomy Wound Management, 56(6):36-44.

12. Saad Setta H, Elshahat A, Elsherbiny $K$ et al. (2011): Platelet rich plasma versus platelet poor plasma in the management of chronic diabetic foot ulcers a comparative study. Int Wound J., 8(3):307-312 